\title{
Nutrition-related Nursing Research
}

\author{
Mary Courtney Moore, Peggi A. Guenter, Josephine Hogan Bender
}

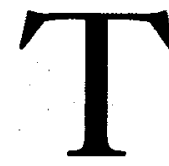

0 identify the contribution of nurses to the nutrition research literature between 1970 and 1984, nursing and multidisciplinary research journals were reviewed.

A total of 104 nutrition research articles with nurses as first author or co-author were identified. More than two thirds of the articles have been published since 1980; only nine had been published prior to 1977 . Of the articles, 55 were primarily nursing research and 49 were the result of team research. More than half (28) of the 55 articles were found in two journals, Nursing Research and The Journal of Parenteral and Enteral Nutrition (JPEN). Most of the articles that were the result of team research were published in JPEN.*

Nurses involved primarily in nursing research had higher educational levels overall than did those involved in team research. Of the 101 nurses involved in nursing research, $79 \%$ had education preparation beyond the bachelor's degree; of the nurses who served as first authors, $76 \%$ were educated beyond the bachelor's level. Of the 57 nurses involved in team research, $20 \%$ had postbaccalaureate education, and one had a doctoral degree.

Even in the nursing research studies there was an emphasis on collaboration, with 36 of the 55 nursing studies involved in collaboration with one or more nurses, physicians, dietitians, or other professionals.

The topics of the studies are shown in Table 1. As can be seen, more articles were related to nutrition support than to any other topic. (Nutrition support may be defined as "the provision of specially formulated and/or delivered intravenous or enteral nutrients to prevent or treat malnutrition." ) (Committee on Standards, 1985). It was found that 19 (34\%) of the nursing studies and $10(20 \%)$ of the team studies dealt with delivery and tolerance of enteral feedings; $11 \%$ of the nursing studies and $43 \%$ of the team studies were concerned with the patient's receiving total parenteral

*A copy of the bibliography of nursing research articles identified is available from the authors. nutrition; and four (7\%) of the nursing studies and 15 $(31 \%)$ of the team studies investigated nutrition assessment methods (see Table 1).

Of the nursing studies 38 were nonexperimental, nine were quasi-experimental or preaxperimental, and eight were experimental. The sample size among the studies ranged from two to 165 .

Many research reports in this survey represented single, isolated investigations. Notable exceptions were the group of articles regarding enteral feeding published by the Tube Feeding Consortium (DeSomery \& Walike, 1975; Hanson, 1973, 1979; Heitkemper, Hanson \& Hansen, 1977; Heitkemper \& Hansen, 1984; Heitkemper, Martin, Hansen, Hanson \& Vanderburg, 1981; Kagawa-Busby, Heitkemper, Hansen, Hanson \& Vanderburg, 1980; Walike et al., 1974; Williams \& Hansen, 1975) and those on eating behaviors and appetite control by Hansen (nee Walike) and her colleagues (DeSomery \& Hansen, 1978; Hansen, DeSomery, Hagedorn \& Kalnasy, 1977; Martyn, Hansen \& Jen, 1984; Walike, 1973).

MARY COURTNEY MOORE, R.N., R.D., M.S.N., was formerly Clinical Specialist, Clinical Nutrition Research Unit, and Assistant Professor of Nursing, Vanderbilt University, Nashville. Tennessee; PEGGI A. GUENTER, R.N., M.S.N., is Clinical Specialist, Nutrition Support Service, Veteran's Administration Hospital, Philadelphia, Pennsylvania, and JOSEPHINE HOGAN BENDER, R.N., M.L.S., is Clinical Care Coordinator, Parenteral and Enteral Nutrition Team, University of Michigan Hospital, Ann Arbor, Michigan. Reprint requests to Ms. Moore, 5008 Overton Ridge Circle, \#218, Fort Worth, TX 76132.

The authors appreciate the help of Kathleen Crocker, M.S.N. chair of the ASPEN Nursing Committee, and Vicki Brendel, R.N., in this project. The authors were members of the American Society for Parenteral and Enteral Nutrition Nursing Research Subcommittee at the time this project was carried out. The views expressed are those of the authors and do not represent an official position of the American Society for Parenteral and Enteral Nutrition, Inc., 8605 Cameron St., Suite 500, Silver Springs, MD 20910.

Supported in part by NIH grant NIADDKD AM 26657

Accepted for publication January 18, 1986. 
The following summaries highlight some of the major contributions made by nurses to the nutrition research literature.

\section{Enteral Feeding}

Hansen and her associates conducted a series of multicenter studies on enteral feeding. They first established a basis for further study by conducting an extensive survey of 121 patients to identify problems associated with tube feeding (Walike et al., 1974). They then conducted studies in lower primates and healthy, paid volunteers to determine optimal flow rate, temperature and volume of tube feedings (Heitkemper et al., 1977; Heitkemper et al., 1981; Heitkemper \& Hansen, 1984; Kagawa-Busby et al., 1980; Williams \& Hansen, 1975). Gastric temperature and motility were measured, as were subjective complaints. Results indicated that flow rates no greater than $60 \mathrm{ml} / \mathrm{min}$ were best tolerated. They also found that adults with normal gastrointestinal function tolerated as much as $750 \mathrm{ml}$ in a single feeding as long as the rate was no greater than $30 \mathrm{ml} /$ min. Conflicting data were obtained regarding the effects of infusions of cold formula (Hanson, 1973; Kagawa-Busby et al., 1980; Williams \& Hansen, 1975), but it appears that a wide range of temperature was tolerated if feedings were given over a period of at least 30 minutes. These studies need to be repeated in ill subjects to determine the effect of various disease states on the results.

Table 1. Toples of Study

\begin{tabular}{lcc}
\hline & \multicolumn{2}{c}{ Number of Studies } \\
\cline { 2 - 3 } & $\begin{array}{c}\text { Nursing } \\
\text { Research }\end{array}$ & $\begin{array}{c}\text { Team } \\
\text { Research }\end{array}$ \\
\hline Enteral tube feeding & 19 & 10 \\
Total parenteral nutrition & 6 & 21 \\
Nutritlonal assessment & 4 & 15 \\
Eating behavlors; appetite control & 5 & - \\
Lactation & 5 & - \\
Cancer & 6 & 2 \\
Obesity and welght reduction & 4 & - \\
Infant feeding & 2 & - \\
Nutrition education methods & 3 & - \\
Modification of urinary pH via & 1 & - \\
dletary means & - & 1 \\
Elderly adults & 55 & 49 \\
TOTAL & &
\end{tabular}

Hanson (1979), a participant in the multicenter enteral feeding research group, studied methods of measuring feeding tubes to determine the length required for nasogastric intubation. Working with 99 cadavers and 5 healthy volunteers, he found that the usual method-insertion of the tube to a point coinciding with the nose-to-earlobe-to-xiphoid process measurement-resulted in proper placement in only about $72 \%$ of cases. He validated a new method, which resulted in proper placement in $91 \%$ of patients. The new technique involves insertion of the tube to a point midway between $50 \mathrm{~cm}$ and the nose-to-ear-xiphoid process measurement.
Another enteral feeding study evaluated the effect of a common nursing practice-offering a pacifier to a tube-fed infant (Measel \& Anderson, 1979). The investigators divided 59 preterm infants into two groups. One group of infants was offered pacifiers during and immediately after tube feeding; the other group was offered pacifiers at any time other than during or immediately after tube feeding. Infants in the experimental group gained weight more rapidly, were able to advance to nipple feedings more rapidly and were hospitalized approximately four days less. Since the original article was published, the beneficial effects of nonnutritive sucking during tube feedings have been documented by the same group (Field et al., 1982) and by Bernbaum, Pereira, Watkins \& Peckham (1981). These studies provide a scientific basis for a nursing action that is often so automatic that it is taken for granted.

Treloar and Stechmiller (1984) designed a study to investigate a concern of many clinicians: the incidence of pulmonary aspiration in patients with artificial airways being fed by tube. They identified 30 ventilator-dependent patients who were to begin continuous intragastric or transpyloric feedings through eight French size tubes. These patients were studied for the duration of tube feeding or until they were extubated. The patients had methylene blue added to their tube feeding formula, and any trace of blue in tracheal or oral secretions was recorded. In addition, daily chest roentgenograms were performed. During the two to 41 days that patients were studied, none had blue-tinged tracheal aspirate or any clinical or radiographic evidence of aspiration pneumonia. One patient had blue-tinged oral secretions, but his cuffed endotracheal tube apparently prevented any aspiration. One shortcoming of the report was the failure to state the number of intragastric versus transpyloric tubes employed. It is possible that a large proportion of the patients studied had transpyloric tubes and that this inhibited regurgitation with resultant pulmonary aspiration. The authors did note that tubes "wandered," that is, a tube might be in a transpyloric location one day but in an intragastric location the next. This study represents an important first step in the evaluation of the safety of enteral tube feedings in a group of patients at high risk for pulmonary aspiration.

\section{Parenteral Nutrition}

Most of the parenteral nutrition articles involved central venous catheter dressing care. For example, Jarrard, Olson \& Freeman (1980) examined the effect of frequency of dressing changes on infection rates. The 15 experimental patients received daily dressing changes, while the 23 control subjects had dressing changes every other day. Patients were followed for the life of the catheter ( 242 patient days and 530 patient days in the experimental and control subjects, respectively). Cultures of the catheter insertion site were done each time the dressing was removed, prior to cleansing of the surrounding skin. There was no growth from insertion-site cultures of any experimental patient, while $3.5 \%$ of such cultures were positive in control subjects. 
There were no positive catheter-tip cultures in the experimental group. However, there were two positive cathetertip cultures in the control group, and the organisms isolated were also isolated from insertion-site cultures. The authors concluded that daily dressing changes were effective in eradicating skin organisms beneath the dressing. This helps to document the value of nursing care in prevention of infectious complications associated with total parenteral nutrition. The authors noted, however, that daily changes were costly in terms of labor and supplies and might best be reserved for patients at high risk for sepsis. In contrast to the findings of Jarrard et al. (1980), other investigators have observed little relationship between skin flora and catheter sepsis (e.g., Sitges-Serra et al., 1984). These disparate findings require further investigation.

The ability of lipid emulsions to support microbial growth was examined by Crocker et al. (1984). They inoculated various types of lipid emulsions with nine different gram negative and gram positive bacteria and Candida albicans and counted the numbers of colony-forming units/ml at zero, six, 12, 24, and 48 hours. All gram negative organisms except Serratia multiplied well in lipid, as did Candida albicans. This study demonstrated that lipid emulsions, unlike glucose/amino acid parenteral nutrition solutions, support bacterial growth. Further clinical studies are needed to document the incidence of significant bacterial growth in lipid emulsions and the incidence of sepsis related to contaminated lipid emulsions.

\section{Nutritional Care of Cancer Patients}

The effect of nursing intervention on nutrition and the performance status of cancer patients was examined by Dixon (1984) in a study of 88 nutritionally at-risk adults with cancer who were being treated as outpatients. The subjects were randomly assigned to one of five study groups.

1. Nutritional supplementation with high protein beverages or foods provided by the nurses and chosen specifically to meet the individual patient's needs and preferences.

2. Relaxation and imagery, using techniques taught to them by the nurse.

3. Both supplementation and relaxation.

4. Visits only (with discussion of eating problems and recommendations provided by the nurse but no specific supplements or relaxation techniques suggested).

5. Control (no intervention for the four-month study period).

After the initial nutrition and performance assessment of all subjects, the patients in the first four groups received home visits by a nurse biweekly for four months; they were given reinforcement, nutrition counseling and attention to other nonnutritional problems during these visits. Reassessment of the subjects at the end of four months revealed that relaxation and imagery yielded the best results in terms of Karnofsky performance score, weight gain or maintenance, arm muscle wuumference and other parameters of nutritional status. Nutritional supplementation in conjunction with relaxation and imagery did not produce an additive effect. The control subjects had the most deterioration in nutrition and performance status. Except for exclusion of breast cancer patients from the study, the investigator did not control for type and stage of tumor or for type of oncologic therapy. It is possible that a particular intervention could be effective in some types of patients but not in others. For example, patients receiving chemotherapy with significant gastrointestinal (GI) toxicity might benefit more from relaxation and imagery than from supplementation; patients receiving chemotherapy without GI toxicity might benefit more from supplementation. Nevertheless this study provides a groundwork for further study and a basis for planning nursing interventions.

\section{Discussion and Research Agenda}

Nursing research has been criticized for its fragmentary nature, with scores of isolated reports but few efforts to follow a systematic line of inquiry through several related investigations (e.g., Downs, 1979; DeTornyay, 1976). Despite the overall lack of continuity in the nutrition articles reviewed, however, there were some encouraging exceptions. Two groups of studies have already been mentioned. On a more modest scale, other investigators also pursued a line of inquiry beyond a single study. Whatley and her colleagues (Whatley, Turner, Dey \& Meier, 1983; Whatley, Turner, Dey, Leonard \& Guthrie, 1984) studied techniques of passing transpyloric feeding tubes, and Welch (1980, 1981) investigated the nutritional status of patients receiving radiation therapy.

An umbrella project developed by nurses involved in nutrition-related research has recently been described (Bergstrom et al., 1984). This research group was joined at various times in its history by several different graduate students, who not only learned research skills and completed their graduate research requirements but also contributed to the knowledge generated by the overall group. This research group could well serve as a model for others.

Over the past few years, nutrition-support nursing has evolved as a specialty. The recent publication of standards of practice for nutrition-support nursing (Forlaw, Crocker, Muttart \& Slocum, 1985), publication of a core curriculum for nutrition support nursing (Kennedy-Caldwell, 1985), and development of a mechanism for certification of nutrition support nurses (National Board of Nutrition Support Certification, 1985) have formally demonstrated the legitimacy of the specialty. Although the number of nurses involved in nutrition support is not known, the American Society for Parenteral and Enteral Nutrition (ASPEN), a multidisciplinary organization for professionals interested and involved in nutrition support, has 510 nurse members.

Some questions that have not been addressed (or have been incompletely addressed) by nurses and other professionals include the psychologic and emotional responses and needs of patients receiving long-term artificial feedings, developmental consequences of long-term artificial feedings in infants and children, nutrition practices for the maintenance and promotion of optimal health, nutrition needs and 
nutrition education needs of older adults, cost containment in nutrition support, cost effectiveness of nutrition support, effects of home nutrition support on family dynamics, reduction of complications of nutrition support, effects of nutritional care in various disease states, use of nutritionrelated nursing diagnoses, nutrition education in nursing and role development of the nutrition support nurse. I

\section{References}

Bergstrom, N., Hansen, B. C., Grant, M., Hanson, R., Kubo, W., Padilla, G., \& Wong, H. L. (1984). Collaborative nursing research: Anatomy of a successful consortium. Nursing Research, 33, 20-25.

Bernbaum, M., Pereira, G. R., Watkins, J. B., \& Peckham, G. J. (1981). Enhanced growth and gastrointestinal function in premature infants given nonnutritive sucking (NNS). Pediatric Research, 15, 650A.

Committee on Standards (1985). Standards for nutrition support: Home patients. Silver Springs, MD: American Society for Parenteral and Enteral Nutrition.

Crocker, K. S., Noga, R., Filibeck, D. J., Krey, S., Markovic, M., \& Steffee, W. P. (1984). Microbial growth comparisons of five commercial parenteral lipid emulsions. Journal of Parenteral and Enteral Nutrition, 8, 391-395.

DeSomery, C., \& Walike, B. C. (1975). Effects of parenteral nutrition on voluntary food intake and gastric motility in monkeys. Communicating Nursing Research, 3, 176-187.

DeSomery, C., Walike, B. C., \& Hansen, B. C. (1978). Regulation of appetite during total parenteral nutrition. Nursing Research, 27, 19-24.

DeTornyay, R. (1976). Nursing research in the Bicentennial year. Boulder, CO: Western Interstate Commission on Higher Education.

Dixon, J. (1984). Effect of nursing interventions on nutritional and performance status in cancer patients. Nursing Research, 33, 330-334.

Downs, F. S. (1979). Creativity in science: What's it ail about. Nursing Research, 28,324 .

Field, T., Ignatoff, E., Stringer, S., Brennan, J., Greenberg, R., Widmayer, S., \& Anderson, G. C. (1982). Nonnutritive suckling during tube feedings: Effects on preterm neonates in an intensive care unit. Pediatrics, 70, 381-384.

Forlaw, L., Grocker, K. S., Muttart, C., \& Slocum, B. (1985). Standards of practice fo nutrition support nursing. Silver Spring, MD; American Society for Parenteral and Enteral Nutrition.

Hansen, B. W., DeSomery, C. H., Hagedorn, P. K., \& Kalnasy, L. W. (1977). Effects of enteral and parenteral nutrition on appetite in monkeys. Journal of Parenteral and Enteral Nutrition, 1, 83-88.

Hanson, R. (1973). Effects of administering cold and warmed tube feedings. Communicating Nursing Research, 6, 136-140.

Hanson, R. (1979). Predictive criteria for length of nasogastric tube insertion for tube feedings. Journal of Parenteral and Enteral Nutrition, 3, 160-163.

Heitkemper, M., Hanson, R., \& Hansen, B. C. (1977). Effects of rate and volume of tube feeding in normal human subjects. Communicating Nursing Research, 10, 71-89.

Heitkemper, M., Martin, D. L., Hansen, B. C., Hanson, R., \& Vanderburg, V. (1980). Rate and volume of intermittent enteral feeding. Journal of Parenteral and Enteral Nutrition, 5, 125-129.

Heitkemper, M., \& Hansen, B. C. (1984). Gastric relaxation prior to enteral feedings. Journal of Parenteral and Enteral Nutrition, 8, 682-684.

Jarrard, M. M., Oison, C. M., \& Freeman, J. B. (1980). Daily dressing change effects on skin flora beneath subclavian catheter dressings during total parenteral nutrition. Journal of Parenteral and Enteral Nutrition, 4, 391-392.

Kagawa-Busby, K. S., Heitkemper, M. M., Hansen, B. C., Hanson, R. L., \& Vanderburg, B. (1980). Effects of diet temperature on tolerance of enteral feedings. Nursing Research, 29, 276-280.

Kennedy-Caldwell, C., (Ed.) (1985). Nutrition support nursing core cirriculum. Silver Springs, MD: American Sociey for Parenteral and Enteral Nutrition.

Martyn, P. A., Hansen, B. C., \& Jen, K. C. (1984). The effects of parenteral nutrition on food intake and gastric motility. Nursing Research, 33, 336-342.

Measel, C. P., \& Anderson, G. (1979). Nonnutritive sucking during tube feedings: Effect on clinical course in premature infants. Journal of Obstetric Gynecologic \& Neonatal Nursing, 8, 265-272

National Board of Nutrition Support Certification (1985). New York: Professional Testing Corporation.

Sitges-Serra, A., Puig, P., Linares, J., Perez, J. L., Farrero, N., Jaurrieta, E., \& Garau, J. (1984). Hub colonization as the initial step in an outbreak of catheterrelated sepsis due to coagulase negative staphylococci during parenteral nutrition. Journal of Parenteral and Enteral Nutrition, 8, 668-672.

Treloar, D. M., \& Stechmiller, J. (1984). Pulmonary aspiration in tube-fed patients with artificial airways. Heart \& Lung, 13, 667-671.

Walike, B. C. (1973). A physiological and behavioral approach to understanding the mechanisms of obesity and anorexia. Communicating Nursing Research, 6 , 201-211.

Walike, B. C., Padilla, G., Bergstrom, N., Hanson, R. L., Kubo, W., Grant, M., \& Wong, H. L. (1974), Patient problems related to tube feeding. Communicating Nursing Research, 7, 89-111.

Welch, D. A. (1980). Assessment of nausea and vomiting in cancer patients undergoing external beam radiotherapy. Cancer Nursing, 3, 365-371.

Welch, D. A. (1981). Nutritional compromise in radiation therapy patients. Journal of Parenteral and Enteral Nutrition, 5, 57-59.

Whatley, K., Turner, W. W., Dey, M., \& Meier, D. E. (1983). Transpyloric passage of feeding tubes. Nutrition Support Services, 3, 18-21.

Whatley, K., Turner, W., Dey, M., Leonard, J., \& Guthrie, M. (1984). When does metoclopramide facilitate transpyloric intubation? Journal of Parenteral and Enteral Nutrition, 8, 679-681

Williams, K. R., \& Hansen, B. C. (1975). Effect of temperature of tube feeding on gastric motility in monkeys. Nursing Research, 24, 4-9.

*Personal communication with ASPEN National Office, June 1985.

The following Sigma Theta Tau members have written items for this issue of IMAGE: Journal of Nursing Scholarship.

Peggi Guenter, Xi Chapter; Edith P. Lewis, Mu Chapter; Janice Meisenhelder, Theta; Mary Moore, Eta Gamma Chapter; Bethel Powers, Epsilon Tau Chapter; Patricia Prescott, Beta Rho; Toni Smith, Epsilon Tau Chapter; Sandra Paul Thomas, Gamma Chi Chapter; John D. Thompson, Delta Mu Chapter; Ruby L. Wilson, Beta Epsilon Chapter.

\section{DEAN OF NURSING UNIVERSITY OF ARIZONA}

University of Arizona invites applications or nominations for the position of Dean of the College of Nursing. University of Arizona, a major research university is located in the Tucson metropolitan area with a student enrollment of approximately 30,000 .

The academic units in the College of Nursing includes the Divisions of Medical-Surgical, Gerontology, Community Health, Maternal-Child and Psychiatric Mental Health Nursing and the Offices of Nursing Research and Continuing Education. There are 53 fulltime faculty and a number of part-time faculty. The College offers the baccalaureate, masters and Ph.D. in nursing. Enrollment in the college is currently 400 students.

The Dean is responsible for promoting research, teaching and service excellence; managing financial resources; and representing the College within the University and the broader community.

Candidates for the position must be prepared to address the challenges of a College of Nursing whose aim is high distinction in research and teaching. Candidates must have a distinguished scholarly record commensurate with appointment to the rank of professor, demonstrated leadership in fostering excellence in research and teaching and the ability to work cooperatively with faculty.

Salary is competitive and the committee will begin reviewing applications on December 1, 1985. Closing date for applications is February 1, 1986. Position is available July 1, 1986

Candidates must possess an earned doctorate with a master's degree in nursing.

Letter of application, resume and three letters of reference should be submitted to:

Dean Paul Marcus

Chair, Search Committee College of Law

University of Arizona

Tucson, AZ 85721

EQUAL OPPORTUNITY AFFIRMATIVE AGTION EMPLOYER 